\title{
GAPPING AND GAPPING-LIKE PHENOMENA
}

\author{
YOSHIO NAKAMURA \\ Yokohama National University
}

\begin{abstract}
This paper presents several arguments for Right Node Raising Analysis of Gapping-like phenomena in Japanese, Korean, and German. Close examination of English data shows that movement is not involved in the derivation of English Gapping constructions, contrary to the recent analyses. And also, the movement analysis is untenable for Gapping-like constructions. On the other hand, under the Right Node Raising analysis, a number of properties of Gapping-like sentences follow straightforwardly. The analysis of this paper offers a key to the mechanism of ellipses in English Gaping and Right Node Raising.*
\end{abstract}

\section{Introduction}

Since Kuno (1973), a number of analyses have been proposed for "backward deletion of verbs" in Japanese:

(1) John-ga Bill-nituite, sosite Mary-ga Susan-nituite John-Nom Bill-about and Mary-Nom Susan-about hanasita.

talked

'John (talked) about Bill, and Mary talked about Susan.'

Saito (1987) explicitly argues that the derivation of (1) involves Right Node Raising (hereafter RNR). On the other hand, Abe and Hoshi (1994) claim that Gapping, but not RNR, is involved at least in some cases, based on their analysis of English Gapping constructions.

The purpose of this paper is to show that the examples observed by Abe and Hoshi (1994) should also be regarded as RNR constructions. In the course of discussion, we will examine the nature of English

* I would like to thank Kunitoshi Takahashi, Yoshio Endo, and Christopher Tancredi and two anonymous EL reviewers for helpful comments and fruitful discussions. I am also grateful to Reinhart Zöllner for having acted as an informant. Remaining inadequacies are my own.

English Linguistics 13 (1996) 1-14 - 1 -

(C) 1996 by the English Linguistic Society of Japan 
Gapping constructions and the similar examples (hereafter, Gappinglike constructions) in Japanese, Korean, and German.

\section{Movement Analysis of Gapping/Gapping-like Constructions}

Abe and Hoshi (1994) argue that the following example should be analyzed as an instance of Gapping constructions: ${ }^{1}$
(2) John-ga Bill, sosite Mary-ga Susan-nituite hanasita. John-Nom Bill and Mary-Nom Susan-about talked 'John (talked about) Bill, and Mary talked about Susan.'

In this example, the shared elements in the first and second conjunct (nituite hanasita 'about talked') do not form any single constituent syntactically. Abe and Hoshi (1994) argue that the shared elements cannot be regarded as right-node raised elements because if, as is generally assumed, RNR can only "move" only a constituent, the example (2) would be assigned the following problematic structure:

( 3 ) [[[John-ga Bill $\left.\mathrm{t}_{\mathrm{j}}\right] \ldots$ [Mary-ga Susan $\left.\left.\left.\mathrm{i}_{\mathrm{i}}\right]\right]\left[\mathrm{t}_{\mathrm{i}} \text {-nituite hanasita }\right]_{\mathrm{j}}\right]$ Under Abe and Hoshi's (1994) analysis, such a problem does not occur. They first assume that English Gapping involves rightward movement of the right-hand remnant out of the target of the deletion operation:

(4) a. John talked about Bill and Mary about Susan.

b. John talked about Bill and [IP Mary [x [x talk $\left.\mathrm{t}_{\mathrm{i}}\right]$ [about Susan $\left.]_{\mathrm{i}}\right]$ ]

c. John talked about Bill and [IP Mary [x [x $\quad \phi$ ] [about Susan $\left.\left.]_{\mathrm{i}}\right]\right]$

See also Jayaseelan (1990) and Abe (1995) for rightward movement analysis of English Gapping. Based on this analysis, Abe and Hoshi

1 An anonymous reviewer informs me that the example (2) is acceptable when the remnants of the first conjunct (John and Bill) are read with forceful stress. Moreover, the reviewer shows that there is some notable difference between examples like (1) and examples like (i):

(i) John-ga kono-heya-de Bill*?(-nituite), sosite Mary-ga John-Nom this-room-in Bill(-about) and Mary-Nom ano-heya-de Susan-nituite hanasita. that-room-in Susan-about talked 'John (talked about) Bill in this room and Mary talked about Susan in that room.'

I leave the detailed examination of the effects of stress on (2)-type sentences for future research. 
(1994) argue that Japanese Gapping-like sentences like (2) involve leftward movement of a remnant:

( 5 ) John-ga $\left[\mathrm{x}\right.$ Bill $\left.\left[\mathrm{x}^{\prime} \phi\right]\right]$ sosite Mary-ga $\left[\mathrm{x} \operatorname{Susan}_{\mathrm{i}}\left[\mathrm{x} \mathrm{t}_{\mathrm{i}}\right.\right.$-nituite hanasita]]

Under this analysis, we do not have to assume the unlikely representation as in (3).

Although Abe and Hoshi's (1994) analysis appears to be attractive, it is questionable in several respects. In the following subsections, let us see the problems of their analysis.

\subsection{English Gapping and Rightward Movement}

In this subsection, let us briefly see the arguments given in Nakamura (1996) against the rightward movement analysis of English Gapping.

Sag (1976) observes that the object of a preposition cannot be the remnant of a Gapping sentence. Jayaseelan (1990) and Abe and Hoshi (1994) argue that this indicates that English Gapping involves rightward movement:

(6) *John spoke to Harry, and Bill $\varnothing$ Mike. $(\varnothing=$ spoke to $)$ Under the rightward movement analysis, the derivation of (6) involves rightward movement as in (7), so that the ungrammaticality of (6) may be attributed to the well-known fact that preposition stranding by Heavy NP Shift is impossible as in (8):

( 7 ) $\ldots$ and Bill ... [spoke [PP to $\left.\left.\mathrm{t}_{\mathrm{i}}\right]\right][\text { [Mike }]_{\mathrm{i}}$

( 8 ) ${ }^{*}$ John counted on $t_{i}$ for support [a total stranger $]_{i}$

However, we should consider examples like (6) carefully. As Sag himself notes, some speakers accept such examples. Then, he speculates that such speakers reanalyze the verb-preposition string as one verb. To support this claim, he shows that the speakers who accept (6) do not allow the following example (9a). Notice here that, as can be seen in (9b), reanalysis cannot apply to the verb-preposition sequence in this case:

(9) a. ${ }^{*}$ Jane left after the first act, and Mary $\varnothing=$ the second act. $\quad(\varnothing=$ left after $)$

b. ${ }^{*}$ The act will be left after (by hundreds of people).

As is pointed out in Nakamura (1996), however, some informants accept (9a) and (10a, b), as well as (6):

(10) a. John arrived at this station, and Bill $\varnothing$ that station. 
b. John arrived at three o'clock, and Bill $\varnothing=$ five o'clock. $(\varnothing=$ arrived at) Notice here that such speakers do not accept $(8),(9 b)$, or the following:

(11) a. ??John arrived at $t_{i}$ yesterday [the station you had recommended $]_{i}$

b. ??John arrived at $t_{i}$ yesterday [the time he had appointed $]_{i}$

If rightward movement is involved in the derivation of English Gapping constructions, the grammaticality of the examples shown so far should be the same, contrary to the facts. Thus, the existence of the speakers who allow (6), (9a) or $(10 a, b)$ indicates that Sag's (1976) observation is no longer evidence for the rightward movement analysis of Gapping. Rather, it poses a serious question to the rightward movement analysis of English Gapping if these examples should count as grammatical examples. $^{2}$

Next, let us consider the examples related to the locality constraint. Kuno (1976) observes that the correspondents in a Gapping construction are most acceptable when they are clause-mates. Under the analysis that English Gapping involves rightward movement, the ungrammaticality of the following (cited from Abe and Hoshi (1994)) would be attributed to the violation of the locality constraint on rightward movement:

(12) a. John thinks that Bill will see Susan, and Harry thinks that Bill will see Mary.

b. ${ }^{*}$ John thinks that Bill will see Susan, and Harry $\varnothing$ Mary. $\quad(\varnothing=$ thinks that Bill will see)

Under the rightward movement analysis, it is argued that (12b) becomes ungrammatical because the second contrasted element Mary in the second conjunct is moved out of the tensed clause, so that the Right Roof Constraint is violated. However, examples like (12b) are not always ungrammatical. As Abe and Hoshi (1994) note, Pesetsky (1982) judges the following example grammatical: ${ }^{3}$

2 As an anonymous reviewer suggests, it might be the case that the speakers who accept (6), (9a) or (10a, b) allow preposition stranding by rightward movement when the preposition becomes covert as a result of Gapping. I have to leave this possibility open.

3 The question of such varied judgments are left open in Abe and Hoshi (1994). 
(13) ?This man knows why you eat spaghetti, and that man macaroni.

Moreover, as noted in Nakamura (1996), (12b) is bad if it is said discourse-initially, but it is perfectly acceptable when Bill is not a focus: ${ }^{4}$

(14) A: Who thinks that Bill will see whom?

B: John thinks that Bill will see Susan, and Harry $\varnothing$ Mary. Although I have no explicit explanation for the question why judgments vary, the observation in (14) at least indicates that (12b) should not count as the Right Roof Constraint violation and cannot be maintained as evidence for the rightward-movement analysis.

So far, we have seen that the rightward movement analysis of English Gapping is not motivated by the data related to the verbpreposition ellipsis and the apparent Right Roof Constraint violation. Rather, careful investigation of such data indicates that the rightward movement analysis for English Gapping is dubious. In the next subsection, let us see the problems of the leftward movement analysis of Gapping-like sentences proposed by Abe and Hoshi (1994) or Sohn (1994), based on the rightward movement analysis of English Gapping.

\subsection{Leftward Movement Analysis of Gapping-like Sentences}

In this subsection, let us see the problems related to Japanese Gapping-like examples.

First, consider the following example:

John-ga niji, sosite
John-Nom two-o'clock and
toutyakusita.

'John (arrived at) two o'clock and Bill arrived at three o'clock.'

In this case, the remnant niji ('two o'clock') is a part of a temporal adjunct. Notice that, in English, even leftward movement cannot

4 As an anonymous reviewer points out, (14A) forces a strict pair-wise interpretation. As a result, the Gapping sentence (14B) becomes acceptable because the arguments left in the sentence can obtain an explicit pair-wise interpretation. As the reviewer notes, this is true to some extent in any gapping-related sentences. See also Kuno (1976) for relevant discussion. 
strand a preposition in a temporal PP as the following example shows:

(16) *What time did John arrive at?

Then, if the derivation of (15) involves leftward movement, it is quite unclear why the movement out of a temporal phrase as in the following is allowed while (16) is prohibited:

(17) John-ga $[\mathrm{x}$ niji $[\mathrm{x} \varnothing]]$ sosite

Bill-ga [x sanji $\mathrm{i}_{\mathrm{i}}\left[\mathrm{x}\right.$ [PP $\mathrm{t}_{\mathrm{i}}$-ni] [vP toutyakusita]]]

Abe and Hoshi (1994) argue that such leftward movement takes place in LF. Even if this is the case, it is quite unclear why LF leftward movement is so unconstrained. ${ }^{5}$

The second question is related to the deletability of postpositions. Sohn (1994) observes the following Korean examples:
a. John-i
Mary-(wa), kulliko Bill-i
Sue-wa
John-Nom Mary-with and Bill-Nom Sue-with
mannassta
met
'Bill met Sue and John Mary.'
b. Mary*(-wa) John(-i), kulliko Sue-wa Bill-i mannassta

As Sohn (1994) shows, any marker (or postposition) can be optionally deleted. What is interesting here is the fact that only the marker on the final remnant can be deleted. Sohn (1994) argues that if LF leftward movement analysis of Abe and Hoshi (1994) is correct, such difference in grammaticality would not be expected. The same is true for Japanese examples:
a. John-ga Mary(-to), sosite Bill-ga Sue-to atta. John-Nom Mary-with and Bill-Nom Sue-with met 'Bill met Sue and John Mary.'
b. Mary*(-to) John-ga, sosite Sue-to Bill-ga atta.

Thus, we would have to say something special for the facts shown above to maintain the LF leftward movement analysis of Gapping-

5 As we will see below, Sohn (1994) proposes the overt leftward movement analysis. However, as Sohn (1994) notes, such analysis cannot handle the Gapping-like examples Abe and Hoshi (1994) pose. Notice also that Abe and Hoshi (1994) observe the following as a grammatical sentence:

(i) John-ga kono riyuu, sosite Mary-ga ano riyuu-de kubininatta John-Nom this reason and Mary-Nom that reason-for was-fired '*John was fired for this reason and Mary that reason.'

However, they do not notice the issue presented here. 
like phenomena. Furthermore, as Sohn (1994) argues, LF leftward movement analysis faces another difficulty. Consider the following examples:

a. Tom-i Sue-lui, kuliko John-i Mary-lui

Tom-Nom Sue-Acc and John-Nom Mary-Acc

Bill-i salanhantako haessta

Bill-Nom love-comp said

'?*John said that Bill likes Mary, and Tom (said ...) Sue.'

b. ${ }^{*}$ Tom-i Sue-lui, kuliko John-i Bill-i

Tom-Nom Sue-Acc and John-Nom Bill-Nom

Mary-lui salanhantako haessta

Mary-Acc love-comp said

In (20b), intervention of the non-contrasted embedded subject (Bill-i) between the two contrasted elements (John-i, Mary-lui) causes a degradation. The same contrast can be seen in Japanese: ${ }^{6}$

$$
\begin{aligned}
& \text { a. ??Tom-ga Sue-o, sosite John-ga Mary-o } \\
& \text { Tom-Nom Sue-Acc and John-Nom Mary-Acc } \\
& \text { Bill-ga aisiteru to itta } \\
& \text { Bill-Nom love comp said } \\
& \text { "?*John said that Bill likes Mary, and Tom (said ...) } \\
& \text { Sue.' } \\
& \text { b. }{ }^{*} \text { Tom-ga Sue-o, sosite John-ga Bill-ga } \\
& \text { Tom-Nom Sue-Acc and John-Nom Bill-Nom } \\
& \text { Mary-o aisiteru to itta } \\
& \text { Mary-Acc love comp said }
\end{aligned}
$$

As Sohn (1994) argues, LF movement analysis would not expect this adjacency requirement.

To capture this characteristic shown above, Sohn (1994) observes the generalization that nothing can intervene the contrasted phrases on both sides of the conjunction. ${ }^{7}$ Notice here that this characteristic may

6 Although (21a) is not perfect, the contrast seems to be clear. As an anonymous reviewer notes, a break seems to be necessary between Mary-o and Bill$g a$ in (21a) to get the intended reading.

7 Sohn (1994) argues that this generalization follows from the analysis that the remnants in the first conjunct move into the specifier position of Focus Phrase. However, this analysis is not tenable. See the arguments presented in section 3 . 
be captured in another way, including the facts observed in (18-19). The examples in (18-19) show that what is to be deleted must be in the right peripheral elements in the first conjunct. The examples in (20-21) show that what is to be elided in the first conjunct must be the counterparts of the right peripheral elements in the second conjunct. These are what we find in English RNR constructions. Terazu (1975) shows that Right Node Raising can only "raise" the final constituent:

(22) a. *John stole from his aunt's casket, and Bill sold to the jeweller at a very high price, the beautiful ring.

b. John stole from his aunt's casket, and Bill sold to the jeweller at a very high price, the beautiful ring which their aunt was very proud of.

In (22b), after the application of Heavy NP Shift, the final constituent is "raised" to the right node. On the other hand, the constituent the beautiful ring is not "heavy," so that it cannot be moved to the final position of the first conjunct by Heavy NP Shift. As a result, RNR cannot be applied to the example. If we assume that Gapping-like sentences in Korean and Japanese are RNR constructions, the same account becomes possible for the ungrammatical examples in (18-19). In these examples, the markers deleted in the first conjuncts are not right-peripheral elements. ${ }^{8}$ This is why they cannot be "right-node raised." Moreover, under the RNR analysis for Gapping-like phenomena in Korean and Japanese, the contrast in (20-21) also follows straightforwardly. In the ungrammatical examples, the counterpart of the intervening subject in the second conjunct is deleted in the first conjunct. Since it does not occupy the position in the right-peripheral elements, the application of RNR results in an ungrammatical sentence. Thus, we may account for the phenomena shown above, if we regard these Gapping-like phenomena as RNR sentences but not Gapping constructions. Notice that if leftward movement is not involved in the derivation of Gapping-like constructions, it is not surprising that English Gapping does not involve rightward movement.

To sum up, we have seen that Gapping-like phenomena in Korean and Japanese show the properties of RNR constructions. In the next

8 As an anonymous reviewer points out, under the analysis proposed in this paper, RNR cannot be a test for constituency. See also section 4 . 
section, let us examine German Gapping/Gapping-like examples.

\section{German Examples}

German is a so-called 'verb-second' language. It shows SOV order in subordinate clauses whereas in main clauses a tense-bearing verb appears immediately after the initial constituent:

(23) a. Ich weiss, dass er zu viel Arbeit hat.

I know that he too much work has

'I know that he has too much work.'

b. Er hat zu viel Arbeit.

he has too much work

'He has too much work.'

Interestingly, German shows both Gapping and Gapping-like phenomena:

a. Johann liebt Maria und Benjamin $\varnothing$ (=liebt) Luzia.

'Johann loves Maria and Benjamin (loves) Luzia.'

b. Ich glaube, dass Johann Maria $\varnothing$ (=liebt) und Benjamin liebt Luzia.

'I think that Johann (loves) Maria and Benjamin loves Luzia.'

If (24a) involves Gapping while (24b) involves RNR, we expect they show different properties. Consider the following example:

(25) Dieses Schiff setzt über den Fluss, jenes $\varnothing$ über das this ship go over the river that over the Meer.

sea.

'This ship goes over the river, and that ship goes over the sea.'

In this example, the deletion operation leaves the remnant über das Meer ('over the sea') in the second conjunct. On the other hand, my informant judges the following example ungrammatical:

(26) ${ }^{*}$ Dieses Schiff setzt über den Fluss, jenes $\varnothing$ das Meer. this ship go over the river that the sea. In (26), the deletion operation elides setzt über ('go over'). With this in mind, let us consider Gapping-like cases. German in colloquial usage allows the following:

(27) a. Da weiss ich nichts von.

it know I not about 
'I don't know about it.'

b. ... weil da niemand gegen war

because it nobody against was

'... because nobody was against it'

In (27a), $d a$ ('it') is separated from von ('about'), and in (27b) $d a$ is separated from gegen ('against'). Now consider the following:

(28) ... weil da einige und hier alle gegen waren because it some and that all against were

'.. because some were against it and all were against that' According to my informant, this is a possible structure (though it is unnatural). ${ }^{9}$ The point here is that not only the verb waren ('were') but also gegen ('against') may be elided in this case, contrary to the Gapping example (26). This fact falls under the RNR analysis of Gapping-like sentences. We may assume that, after the movement of $d a$ ('it'), the right-peripheral elements in the first conjunct gegen waren ('against were') are deleted (or "right-node raised"):
a. $\quad \ldots$ weil da $a_{i}$ einige $\left[t_{i}\right.$ gegen waren] $\ldots$
b. $\quad \ldots$ weil da $a_{i}$ einige [
$\varnothing$

Thus, the ungrammaticality of (26), a Gapping sentence, has nothing to do with the derivation of an RNR construction (28) as in (29). Then, the Gapping-like examples of German may be best regarded as RNR sentences as well as those found in Korean and Japanese. Assuming the movement analysis of Gapping, one might argue that the ungrammaticality should be attributed to the unextractability of das Meer ('the sea'), leaving über ('over'). However, German data pose a question to the movement analysis. German, an SOV language, allows scrambling, that is, an optional leftward movement. Then, the movement analysis would assume that leftward movement of PP in the derivation of (25). ${ }^{10}$ However, as observed in Nakamura (1996), such an operation is impossible as we can see in the following:

(30) ${ }^{*}$ Dieses Schiff [über das Reer] $]_{i}$ setzt $t_{i}$ this ship over the sea go 'This ship goes over the sea.'

$9 \mathrm{My}$ informant pointed out to me that in this case, $d a$ and hier do not have clear contrastive meaning. This might be relevant for the unnaturalness of this example.

10 See Fukui (1993) for the precise mechanism that determines the direction of optional movements. 
Sohn (1994) claims that Gapping-like sentences in Korean involves overt movement of the contrastive focus phrases, that is, remnants in the first clause, to SPEC-FP (Focus Phrase). The ungrammaticality of (30), however, leads us to the conclusion that Gapping-like constructions in German (and probably in Korean) do not involve such movement in the overt syntax. If such movement takes place at LF as Abe and Hoshi (1994) argues, it still remains unclear why this sort of leftward movement is allowed only in LF, but not in the overt syntax. ${ }^{11}$ Moreover, overt movement analysis proposed by Sohn (1994) faces another problem. Consider the following example:

(31) ... weil da einige gegen und niemand für war because it some against and nobody for was '.. because some were against, and nobody was for it' If the contrastive elements in the first clause are all moved to SPECFP, $d a$ ('it') must be extracted out of the moved elements in FP-SPEC as in the following:

$$
\begin{aligned}
\ldots d_{a} \ldots & {\left[\left[\text { FP } \text { einige }_{j}\left[t_{i} \text { gegen }\right]_{k}\left[\ldots t_{j} \ldots t_{k} \ldots\right]\right] \ldots\right.} \\
& \text { und } \\
& {\left[\left[\text { FP niemand }{ }_{1}\left[t_{i} \text { gegen }\right]_{m}\left[\ldots t_{1} \ldots t_{m} \ldots\right]\right] \ldots\right.}
\end{aligned}
$$

However, this scenario is hard to accept because we have to say that extraction out of an element moved into a specifier position causes no violation here. ${ }^{12}$ Such a problem does not occur under our analysis, where Gapping-like constructions are claimed to be RNR sentences.

To sum up this section, we have seen that German data lead us to suspect that Gapping-like phenomena do not involve leftward movement either in the overt syntax or in LF. We have also seen that the

11 As an anonymous reviewer notes, (30) would be a violation of the verb-second constraint. Whatever the exact nature is, one would have to answer the question why such a constraint does not hold for Gapping-like constructions under the movement analysis.

12 For example, Takahashi (1994) claims that extraction out of a moved element causes a violation of chain uniformity requirement:

(i ) ${ }^{*} \mathrm{XP} \ldots\left[\mathrm{YP} \mathrm{t}_{\mathrm{XP}}\left[\mathrm{YP} \ldots \mathrm{t}_{\mathrm{XP}} \ldots\right]\right] \ldots \mathrm{t}_{\mathrm{YP}} \ldots$

In (i), XP is extracted out of a moved element YP. To satisfy the MCL ("minimize chain link") condition, XP has to first adjoin to YP. The resulting representaion causes the chain uniformity condition violation because the head of YP chain $\left(\left[\mathrm{YP}_{\mathrm{P}} \mathrm{t}_{\mathrm{XP}}\left[\mathrm{YP} \ldots \mathrm{t}_{\mathrm{XP}} \ldots\right]\right]\right)$ is not identical to the tail $\left(\mathrm{t}_{\mathrm{YP}}=\mathrm{YP}\right)$. However, the German example (31) is perfectly grammatical. Thus, it seems hard to maintain Sohn's (1994) analysis of Gapping-like constructions. 
Gapping-like phenomena shown so far fall under the RNR analysis.

\section{Conclusion and Further Issues}

In this paper, we have examined a number of properties of Gapping and Gapping-like constructions. Gapping-like examples found in Korean, Japanese, and German show that they should be regarded as RNR constructions but not Gapping constructions. Notice here that RNR is misnomer. In the literature, it has been argued that RNR sentences do not involve rightward movement. See Kimura (1986) for extensive discussion of this issue. If this is the case, the Japanese example (2), repeated below, would be assigned the representation like (33):

(2) John-ga Bill, sosite Mary-ga Susan-nituite hanasita. John-Nom Bill and Mary-Nom Susan-about talked 'John (talked about) Bill, and Mary talked about Susan.'

(33) [IP [IP John-ga Bill $\varnothing$ (=nituite hanasita)] sosite [IP Mary-ga Susan-nituite hanasita]]

At this point, we have to abandon the assumption that RNR can only apply to a constituent. In other words, the elided elements need not form a constituent. Remember that this is the case in English Gapping constructions. As we have seen in section 2, a verb-preposition string may be elided. This issue requires more extensive research to determine the exact nature of ellipsis. We must leave the detailed examination of this point for future research.

Throughout this paper, we have argued that the movement analyses of Gapping/Gapping-like phenomena are problematic. Still, our analysis leaves the ungrammaticality of the following cited from Abe and Hoshi (1994) unanswered:
a. ??Harry-ga imiron, sosite Alfonse-ga toogoron-o Harry-Nom semantics and Alfonse-Nom syntax-Acc kenkyuusiteiru gengogakusya-ni atta. is studying linguist -to met
'*Alfonse met a linguist who studies syntax and Harry semantics.'
b. ??John-ga suugaku, sosite Mary-ga eego-o John-Nom math and Mary-Nom English-Acc benkyoosuru mae-ni syokuzisita. studied before ate 
"*Mary had a meal before she studied English, and John math.'

These examples show island effects. This implies that some movement is involved here. Suppose that, for example, what is involved is movement of some feature, along the line of Chomsky (1995). As we have seen, Sohn (1994) claims that Korean and Japanese exploit overt focus movement of the remnants in Gapping-like constructions. Then, suppose that contrastive-feature is moved in Gapping/Gapping-like constructions. ${ }^{13}$ Then, it might be possible to maintain the analysis that no $\mathrm{X}^{\mathrm{max}}$-movement is involved in the derivation of Gapping/ Gapping-like constructions as we argued so far, and the island effects might be attributed to the constraints on feature movement. It also requires more extensive research, and we leave this issue for future research.

13 See Neijt (1979) for island effects in English Gapping constructions. Notice here again that adjunct PPs do not form an island as shown in (10) and (15). Thus, the tensed clause in an island seems relevant for the ungrammaticality of (34) or the following cited from Johnson (1994):

(i ) ${ }^{*}$ John left after he met Deniro, and Bill $\varnothing$ (=left after he met) Streep.

Note also that, as Moltmann (1993) observes, the Gapping rule may reach into a finite clause when the subject of the embedded clause is coreferent with the subject left as a remnant:

(ii ) $\mathrm{John}_{\mathrm{i}}$ believes that he $\mathrm{e}_{\mathrm{i}}$ has met Sue, and Bill $\mathrm{j} \varnothing$ (=) believes that he $\mathrm{j}_{\mathrm{j}}$ has met) Mary.

Moreover, as an anonymous reviewer points out, some contextual setting may be relevant. The reviewer observes that the following (iii) sounds better than (iv):

(iii) Harry-ga imiron, Alfonse-ga toogoron-o benkyoo-suru Harry-Nom semantics Alfonse-Nom syntax-Acc study gakusei-o osieta. student-Acc taught

'Alfonse taught a student who studies syntax, and Harry semantics.'

(iv) Harry-ga imiron, Alfonse-ga toogoron-o benkyoo-suru Harry-Nom semantics Alfonse-Nom syntax-Acc study gakusei-o sikatta. student-Acc scolded

'Alfonse scolded a student who studies syntax, and Harry semantics.' I have no explicit idea for these facts and I must leave them for future research. 


\section{REFERENCES}

Abe, Jun (1995) “Ellipsis: Deletion, Copying or Both?” ms., Toyo Women's College.

Abe, Jun and Hiroto Hoshi (1995) "Gapping and P-stranding," ms., Toyo Women's College and SOAS, University of London.

Chomsky, Noam (1995) The Minimalist Program, MIT Press, Cambridge, MA.

Fukui, Naoki (1993) "Parameters and Optionality," Linguistic Inquiry 24, 399-420.

Jayaseelan, K.A. (1990) "Incomplete VP Deletion and Gapping," Linguistic Analysis 20, 64-81.

Johnson, Kyle. (1994) "Bridging the Gap," ms., University of Massachusetts, Amherst.

Kimura, Norimi (1986) "Right Node Raising: A Null Anaphor Analysis," English Linguistics 3, 118-133.

Kuno, Susumu (1973) Studies in Japanese Grammar (Nihon-Bunpoo Kenkyuu), Taisyukan, Tokyo.

Kuno, Susumu (1976) "Gapping: a Functional Analysis," Linguistic Inquiry 7, 300-318.

Moltmann, Friederike (1993) Coordination and Comparatives, Doctoral dissertation, MIT.

Nakamura, Yoshio (1996) "Kuusyoka-no Idoubunseki-ni Taishite (Against Movement Analyses of Gapping)," ms., Yokohama National University.

Neijt, Anneke (1979) Gapping: A Contribution to Sentence Grammar, Foris, Dordrecht.

Pesetsky, David (1982) Paths and Categories, Doctoral dissertation, MIT.

Sag, Ivan (1976) Deletion and Logical Form, Doctoral dissertation, MIT.

Saito, Mamoru (1985) Some Asymmetries in Japanese and Their Theoretical Consequences, Doctoral dissertation, MIT.

Sohn, Keun-Won (1994) "On Gapping and Right Node Raising," Explorations in Generative Grammar, ed. by Young-Sun Kim, Byung-Choon Lee, Kyoung-Lae Lee, Hyun-Kwon Yang, and Jong-Yurl Yoon. 589-611, Hankuk Publishing, Seoul.

Takahashi, Daiko (1994) Minimality of Movement, Doctoral dissertation, University of Connecticut.

Department of English

Faculty of Education

Yokohama National University

156 Tokiwadai, Hodogaya-ku

Yokohama, Kanagawa 240

e-mail: yoshio@ed.ynu.ac.jp 